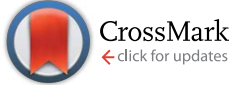

Cite this: J. Mater. Chem. A, 2016, 4, 13555

Received 26th April 2016

Accepted 4th August 2016

DOI: $10.1039 / \mathrm{c} 6 \mathrm{ta0} 3471 \mathrm{c}$

www.rsc.org/MaterialsA

\title{
Electro-precipitation via oxygen reduction: a new technique for thin film manganese oxide deposition $\uparrow$
}

\author{
Gijs Vanhoutte, ${ }^{\text {a }}$ Minxian Wu, ${ }^{a}$ Stijn Schaltin, ${ }^{a}$ Felix Mattelaer, ${ }^{b}$ \\ Christophe Detavernier, ${ }^{b}$ Philippe M. Vereecken, ${ }^{c}$ Koen Binnemans ${ }^{d}$ \\ and Jan Fransaer*a
}

\begin{abstract}
Manganese oxide was deposited from a non-aqueous solution, dimethyl sulfoxide (DMSO), via the reduction of dissolved oxygen. The formed superoxide radical ion $\left(\mathrm{O}_{2}^{-\cdot}\right)$ reacts rapidly with the manganese ions forming a smooth and thin film $(80 \mathrm{~nm})$ of manganese oxide. From an in situ EQCM study, it could be concluded that $\mathrm{MnO}_{2}$ was the most probable oxide which was deposited at an average growth rate of $0.049 \mu \mathrm{g} \mathrm{s}^{-1}$ or $0.077 \mathrm{~nm} \mathrm{~s}^{-1}$. Since the direct deposition of a phase pure $\mathrm{MnO}_{2}$ layer was not confirmed by XRD, it is more likely that a variety of manganese oxides has been deposited during the electro-precipitation reaction and thus further optimization or post-treatments are required to obtain an active manganese oxide layer for thin film deposits. The key property of this new deposition technique is the self-limiting behavior, proven by rotating ring-disk electrode experiments. This is crucial to electrodeposit thin films conformally on high aspect ratio structures for 3D all-solid-state lithium-ion batteries or supercapacitors.
\end{abstract}

\section{Introduction}

Rechargeable all-solid-state batteries will play an important role in future devices such as small medical implants, smart textiles, integrated lighting solutions and many other autonomous devices. Due to the lack of a liquid electrolyte, all-solid-state batteries are inherent safer and thus suited for a broader range of applications. Planar solid-state thin film batteries are rapidly emerging but reveal several drawbacks, such as a relatively low energy density. ${ }^{1}$ In order to overcome these limitations a 3Dintegrated all-solid-state battery concept with a significantly increased surface area has been developed. ${ }^{2-6}$ By using etching techniques known from microchip manufacturing, high-aspect ratio structures can be made, e.g. trenches, holes, pillars, etc. on materials like silicon. The challenge is to find low-cost and fast

${ }^{a}$ KU Leuven, Department of Materials Engineering, Kasteelpark Arenberg 44, box 2450, B-3001 Leuven, Belgium. E-mail: gijs.vanhoutte@kuleuven.be; jan.fransaer@ kuleuven.be

${ }^{b}$ Ghent University, Department of Solid State Sciences, Krijgslaan 281 S1, B-9000 Gent, Belgium

'Imec, Kapeldreef 75, B-3001 Leuven, Belgium

${ }^{d}$ KU Leuven, Department of Chemistry, Celestijnenlaan 200F, B-3001 Leuven, Belgium $\dagger$ Electronic supplementary information (ESI) available: Cyclic voltammogram, SEM image and EDX spectrum of the manganese electrodeposition without the presence of dissolved oxygen in DMSO. Cyclic voltammograms measured during the EQCM experiment of the electro-precipitation of $\mathrm{Mn}_{x} \mathrm{O}_{y}$. Detailed (in situ) XRD patterns of the $\mathrm{Mn}_{x} \mathrm{O}_{y}$ layers. Energy storage data. See DOI: $10.1039 /$ c6ta03471c deposition techniques for battery materials that are able to cover the 3D structures in a conformal manner. ${ }^{6}$ Electrodeposition is such a technique, because the amount of deposited material can be controlled via the applied charge through the electrodes. In order to conformally coat 3D substrates by electrodeposition, two approaches can be used. The first method is controlling the charge transfer kinetically. Since in this case the deposition is not limited by diffusion of ionic species, deposition rates are equal everywhere on the high-aspect ratio structures and are thus only controlled by the applied (pulsed) currents. On the other hand, if the deposition is mass-transport controlled, the film thickness will vary along the structures. An alternative method to obtain a conformally covered substrate is via a self-limiting deposition technique: by depositing a material which is sufficiently blocking the electron-transport through the deposited layer, a higher growth rate is obtained on the more conductive original substrate. Upon layer formation, the electrodeposition reaction is inhibited and eventually no further electron transport is possible. At that moment, the charge transfer reaction stops and a closed layer is obtained. This approach has been demonstrated for polymer electrolytes. ${ }^{7,8}$

Manganese dioxide $\left(\mathrm{MnO}_{2}\right)$ can be used as an alternative material to $\mathrm{LiCoO}_{2}$ or $\mathrm{LiFePO}_{4}$ in the positive electrode of lithium-ion batteries. It offers the advantages of a low cost and high capacity (theoretically $308 \mathrm{~mA} \mathrm{~h} \mathrm{~g}^{-1}$ ). ${ }^{9}$ Although manganese dioxide has been used in primary and secondary batteries (both aqueous and non-aqueous), its incorporation into 
secondary non-aqueous lithium-ion batteries has encountered difficulties. Evolution of structural water present in manganese dioxide during cycling results in gassing and loss of cell capacity, while heat-treatment to remove water leads to the transition from $\gamma-\mathrm{MnO}_{2}$ to a mixed $\gamma / \beta-\mathrm{MnO}_{2}$ phase ${ }^{\mathbf{1 0 , 1 1}}$ causing significant capacity loss upon cycling. ${ }^{12} \gamma-\mathrm{MnO}_{2}$ is most commonly prepared via electrodeposition from aqueous solutions and is called electrolytic manganese dioxide (EMD). Different techniques were used for the anodic deposition, including galvanostatic, potentiostatic and pulse deposition. ${ }^{13,14}$ Sarciaux et al. showed that the structure of the EMD depends on the deposition conditions of temperature, $\mathrm{pH}$ and current density. ${ }^{15,16}$ Many studies have been devoted to solving the issue of structural water in $\mathrm{MnO}_{2}$. These approaches such as heat treatment improve the quality of the batteries. However, these extra processes add costs to the industrial production of $\mathrm{MnO}_{2}$ as a battery material. A single-step deposition process from non-aqueous solutions would eliminate these issues with structural water.

Besides as a battery material, $\mathrm{MnO}_{2}$ is also used for supercapacitors. There is currently a lot of research towards transition metal oxides that exhibit pseudocapacitance, which arises when reversible redox reactions occur. ${ }^{17}$ However $\mathrm{MnO}_{2}$ does not possess a high electronic conductivity, ${ }^{18}$ as a result, charge storage in $\mathrm{MnO}_{2}$ occurs within a thin layer of the surface. ${ }^{19}$ This was also proven by Cross et al. for electrolytic manganese dioxide, where a significantly higher capacitance was measured for a thin film of approx. $40 \mathrm{~nm}^{.{ }^{2021}}$ As a consequence composite systems look very promising. They combine the good conductivity from materials such as graphene, gold, carbon nanotubes, etc. with the high pseudo-capacitance from $\mathrm{MnO}_{2}$ thin films. ${ }^{22-25}$

In this paper, a new electrodeposition method is proposed for the synthesis of manganese oxide. An electro-precipitation reaction via oxygen reduction is used to deposit manganese dioxide from non-aqueous solutions. Thanks to the poor electron conductivity of the electro-precipitated oxides, a selflimiting process is obtained and a closed thin film is formed on a planar substrate.

\section{Experimental}

\subsection{General methods}

All electrochemical experiments were performed at room temperature in a three-electrode set-up, using an Autolab 302N potentiotstat with NOVA 1.10.3 software. All reported potential values are relative to a real reference electrode which consists of a silver wire (Chempur, 99.98\%) in a glass tube with a porous ceramic frit filled with a $0.1 \mathrm{M} \mathrm{AgNO}_{3}$ and $1 \mathrm{M} \mathrm{LiTf}_{2} \mathrm{~N}$ solution in DMSO, unless mentioned otherwise. A platinum coil was used as a counter electrode. For the EQCM experiments, a Quartz Crystal Microbalance (Maxtex RQCM) was used with a platinumcoated QCM-crystal (1 inch) with an electrochemically active surface area of $1.27 \mathrm{~cm}^{2}$. The crystal was mounted in a homemade cell to enable bubbling of oxygen gas through the electrolyte solution, but the commercial crystal holder was used in combination with Kalrez O-rings (Fig. S1†). SEM imaging was performed using a Nova600 NanoLab, equipped with a dual beam SEM/FIB for nanoscale characterization of the thin film deposits. Crystallization of $\mathrm{Mn}_{x} \mathrm{O}_{y}$ thin films in a controlled atmosphere $\left(95 \% \mathrm{O}_{2}, 5 \% \mathrm{He}\right)$ was studied by in situ heating XRD (Bruker D8 Discover with experimental heating chamber). ${ }^{26} \mathrm{~A}$ linear detector was used, recording a diffraction pattern with a $2 \theta$ range of $28^{\circ}$ to $45^{\circ}$ every 5 seconds within a temperature range of 25 to $1000{ }^{\circ} \mathrm{C}$ (with a heating rate of $0.2^{\circ} \mathrm{C} \mathrm{min}{ }^{-1}$ ). The RRDE experiments were conducted using a platinum disk $(\phi=$ $4.57 \mathrm{~mm})$ and ring $\left(\phi_{\text {inner }}=4.93 \mathrm{~mm}, \phi_{\text {outer }}=5.38 \mathrm{~mm}\right.$, both 99.99\% Pt, mirror polished, Pine Instrument E7R8 RRDE tips), separated by an insulating PTFE thin gap $(180 \mu \mathrm{m})$. The electrochemical activity and energy storage capability of the $\mathrm{Mn}_{x} \mathrm{O}_{y}$ thin films were measured via cyclic voltammetry. For the capacitance data, a $0.5 \quad \mathrm{M} \mathrm{K}_{2} \mathrm{SO}_{4}$ (Sigma-Aldrich, $\geq 99 \%$ ) aqueous solution was used and a $\mathrm{Ag} / \mathrm{AgCl}$ reference electrode and a Pt counter electrode. For lithiation and delithiation a $1 \mathrm{M}$ $\mathrm{LiClO}_{4}$ (Sigma-Aldrich, 99.99\% battery grade) in anhydrous propylene carbonate (Sigma-Aldrich, 99.7\%) was used.

\subsection{Synthesis}

Manganese(II) bis(trifluoromethylsulfonyl)imide, $\operatorname{Mn}\left(\operatorname{Tf}_{2} \mathrm{~N}\right)_{2}$, was synthesized by stirring a solution of manganese(II) oxide (1.00 g; $14.1 \mathrm{mmol}$ ) and hydrogen bis(trifluoromethylsulfonyl) imide ( $80 \%$ solution in water) $(9.91 \mathrm{~g} ; 28.2 \mathrm{mmol})$ in water for 3 hours at $75{ }^{\circ} \mathrm{C}$. The remaining solids were filtered; subsequently the excess solvent was removed on a rotary evaporator and the product was dried at a vacuum line (100-200 Pa), resulting in $\mathrm{Mn}\left(\mathrm{Tf}_{2} \mathrm{~N}\right)_{2}$ with a melting point of $58{ }^{\circ} \mathrm{C}$. Anhydrous dimethyl sulfoxide (DMSO) $\left(\geq 99.9 \%,<0.005 \% \mathrm{H}_{2} \mathrm{O}\right.$ ) was purchased from Sigma-Aldrich and used as received. All reagents and solutions were prepared and stored inside an argon-filled glovebox with oxygen and water concentrations less than $1 \mathrm{ppm}$. An electrolyte stock solution of $1 \mathrm{M} \mathrm{Mn}\left(\mathrm{Tf}_{2} \mathrm{~N}\right)_{2}$ in DMSO was prepared inside the glovebox, from which dilutions were made to obtain lower $\mathrm{Mn}^{2+}$ concentrations in solution. Once assembled, the electrochemical cell was taken outside of the glovebox and oxygen was dissolved in the electrolyte solutions by bubbling oxygen gas (Air Liquide Alphagaz, 99.999\% purity, $\mathrm{H}_{2} \mathrm{O}<0.5 \mathrm{ppm}$ ) through the electrolyte solution for 30 minutes prior to the electrochemical experiments.

\section{Results and discussion}

\subsection{Oxygen reduction and oxygen evolution reactions in DMSO without $\mathrm{Mn}^{2+}$ ions}

The oxygen reduction reaction (ORR) and the oxygen evolution reaction (OER) were studied by cyclic voltammetry (Fig. 1, eqn (1)).

$$
\mathrm{O}_{2}+\mathrm{e}^{-} \rightleftharpoons \mathrm{O}_{2}^{-}
$$

Electrochemical experiments were conducted in oxygensaturated DMSO solutions with tetrabutylammonium perchlorate (TBAP) as the supporting electrolyte. A clear reduction peak and an oxidation peak could be observed, indicating the 


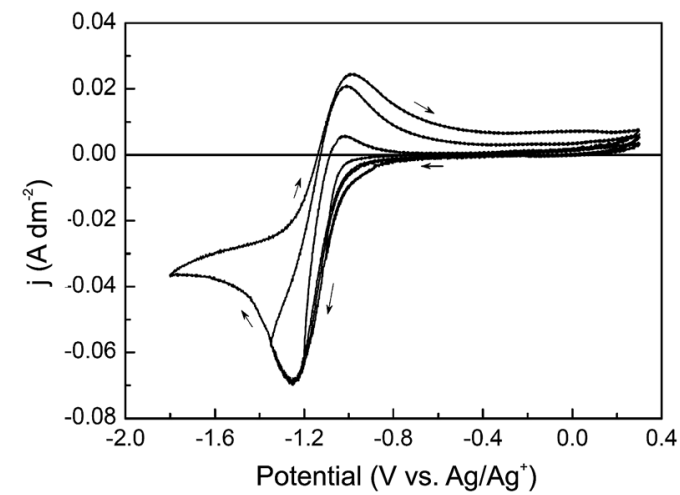

Fig. 1 Cyclic voltammograms of a DMSO solution containing $1 \mathrm{M}$ TBAP and saturated with oxygen gas. Different cathodic vertex potentials were applied, using a glassy carbon disk $(\phi=1 \mathrm{~mm})$ as the working electrode and a platinum coil as the counter electrode. The scan rate was $50 \mathrm{mV} \mathrm{s}^{-1}$.

reversibility of the reduction of oxygen in DMSO with TBAP. These experimental observations are similar to what had been described by Laoire et al. in a more detailed study. ${ }^{27}$

Due to the reversibility of the reduction of oxygen, the diffusion coefficients of both oxygen and superoxide radicals can be obtained by means of rotating ring disk electrode (RRDE) experiments. Cyclic voltammetry was applied on the disk, while the ring was kept at a potential of $-0.2 \mathrm{~V} v s$. $\mathrm{Ag} / \mathrm{Ag}^{+}$(Fig. 2). During the cathodic scan, oxygen was reduced to the superoxide radical ion $\mathrm{O}_{2}{ }^{-}$, but when the $\mathrm{O}_{2}{ }^{-\cdot}$ ions reached the ring, they were re-oxidized to $\mathrm{O}_{2}$. At lower rotation speed, small oxidation peaks could be observed on the reverse scan on the disk which illustrates the slow diffusion of $\mathrm{O}_{2}{ }^{-}$in the solution. At slow scan rates, all the superoxide radicals have enough time to move from the disk to the ring, so there was no oxidation peak on the disk even at low rotation speed.

The RRDE was calibrated using a ferri/ferro redox couple and a collection efficiency of $20.4 \%$ was calculated based on the following equation:

$$
N_{\mathrm{k}}=-\frac{i_{\text {ring }}}{i_{\text {disk }}}
$$

where $N_{\mathrm{k}}$ is the collection efficiency, and $i_{\text {ring }}$ and $i_{\text {disk }}$ are the limiting current on the ring and disk, respectively. The experimentally determined value of $20.4 \%$ is lower than the RRDE's geometrical defined collection efficiency of $22 \%$.

It takes time for the superoxide radical ion to migrate from the disk to the ring. The transient time depends on the diffusion coefficient of the superoxide radical ion and the rotation speed of the rotating ring-disk electrode, and is given by eqn (3): ${ }^{28}$

$$
T_{\mathrm{s}}=K\left(\frac{\nu}{D}\right)^{1 / 3} \omega^{-1}
$$

where $T_{\mathrm{s}}$ is the transient time (s), $\omega(\mathrm{rpm})$ is the rotation speed, $K\left(=43.1\left[\log \left(r_{2} / r_{1}\right)\right]^{2 / 3}\right)$ is a constant depending on the geometry of the rotating ring-disk electrode, and $\nu\left(\mathrm{m}^{2} \mathrm{~s}^{-1}\right)$ is the kinematic viscosity of the solution, which is $3.48 \pm 0.018 \times 10^{-6}$ $\mathrm{m}^{2} \mathrm{~s}^{-1}$. The transient time can be obtained by stepping the disk

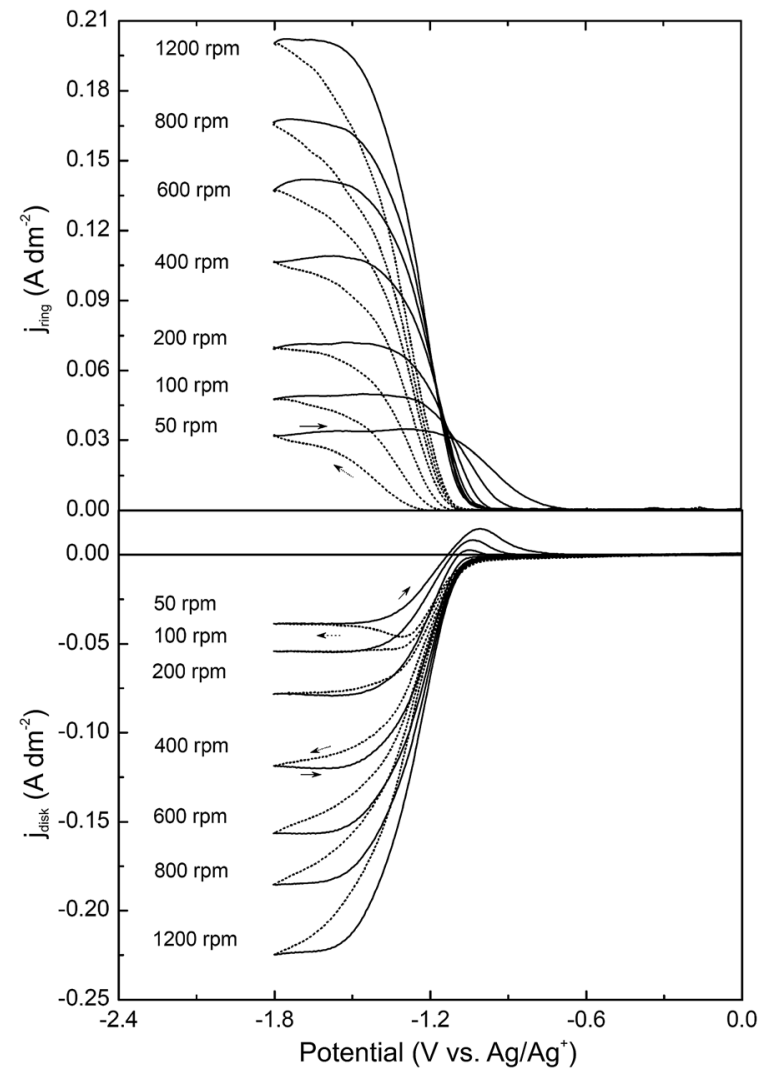

Fig. 2 Disk and ring currents recorded in an oxygen-saturated $1 \mathrm{M}$ TBAP solution in DMSO with different rotation speeds at room temperature. The disk current was generated from the cyclic voltammetry with a scan rate of $50 \mathrm{mV} \mathrm{s}^{-1}$, and the ring was kept at a potential of $-0.2 \mathrm{~V}\left(\mathrm{vs}\right.$. $\mathrm{Ag} / \mathrm{Ag}^{+}$).

potential from open circuit potential to the potential where reduction of oxygen to the superoxide radical ion is diffusionlimited. In the meanwhile, a constant potential where the oxidation of superoxide radical ions to oxygen molecules is diffusion-limited was applied on the ring. When the reduction potential was applied on the disk, oxygen was reduced and the superoxide radical ion moves towards the ring electrode. Before the superoxide radical ion reached the ring, there was no current flow and the time before an oxidation current was detected on the disk is the transient time (Fig. S2a †). The diffusion coefficient of oxygen was obtained in a similar way. Instead of holding the ring potential at $+0.3 \mathrm{~V}\left(v s . \mathrm{Ag} / \mathrm{Ag}^{+}\right)$, the potential was held at $-1.6 \mathrm{~V}\left(v s . \mathrm{Ag} / \mathrm{Ag}^{+}\right)$where the reduction of oxygen is diffusion limited (Fig. S2b $\dagger$ ). Based on the linear relationship between the transient time and the inverse of the rotation speed, the diffusion coefficient of $\mathrm{O}_{2}{ }^{-\cdot}$ could be derived from the slope (Fig. 3). The diffusion coefficient of $\mathrm{O}_{2}{ }^{-\cdot}$ is 3.4 $10^{-10} \mathrm{~m}^{2} \mathrm{~s}^{-1}$ and the diffusion coefficient of $\mathrm{O}_{2}$ is $3.010^{-9} \mathrm{~m}^{2}$ $\mathrm{s}^{-1}$ which is 3 times greater than the value reported by Laoire et $a .^{27}$

The concentration of oxygen in the DMSO can be calculated from the Levich equation:

$$
j_{\mathrm{L}}=0.62 n F \nu^{-1 / 6} D^{2 / 3} \omega^{1 / 2} c
$$




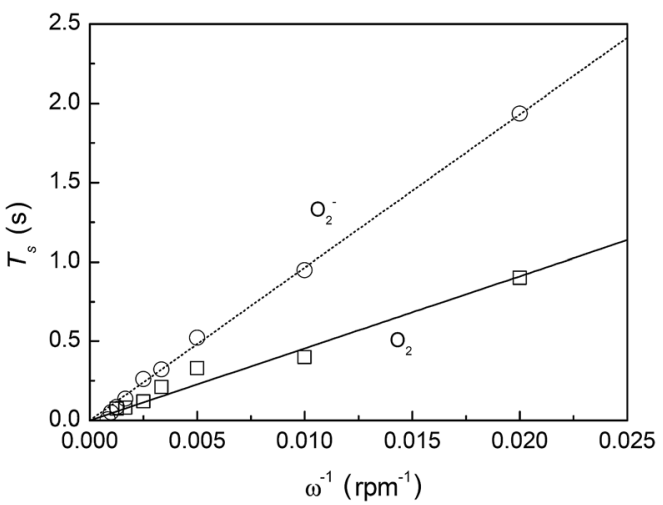

Fig. 3 The transient time change with the inverse of the rotation speed in an oxygen-saturated 1 M TBAP solution in DMSO.

where $j_{\mathrm{L}}$ is the limiting current density $\left(\mathrm{A} \mathrm{m}^{-2}\right), F$ is the faradic constant, $D\left(\mathrm{~m}^{2} \mathrm{~s}^{-1}\right)$ is the diffusion coefficient, $\omega\left(\mathrm{rad} \mathrm{s}^{-1}\right)$ is the rotation speed, and $c\left(\mathrm{~mol} \mathrm{~m}^{-3}\right)$ is the concentration of dissolved oxygen. The limiting currents at different rotation speeds were read from Fig. 2. The concentration of $\mathrm{O}_{2}$ in DMSO was calculated to be $1.9 \mathrm{mM}$, which is comparable with the value reported by Laoire, $2.1 \mathrm{mM}$.

If the concentration is known, the diffusion coefficient of $\mathrm{O}_{2}$ can be also derived from the Randles-Sevcik equation:

$$
j_{\mathrm{p}}=0.4463\left(\frac{\mathrm{F}^{3}}{\mathrm{R} T}\right)^{1 / 2} n^{3 / 2} D^{1 / 2} c v^{1 / 2}
$$

where $j_{\mathrm{p}}\left(\mathrm{A} \mathrm{m}^{-2}\right)$ is the peak current density of the cyclic voltammogram, $\mathrm{F}$ is the Faraday constant (96 $485.33 \mathrm{C} \mathrm{mol}^{-1}$ ), $\mathrm{R}$ is the gas constant $\left(\mathrm{J} \mathrm{mol}^{-1} \mathrm{~K}^{-1}\right), T$ is the temperature $(\mathrm{K}), n$ is the number of electrons involved in the reaction, and $\nu\left(\mathrm{V} \mathrm{s}^{-1}\right)$ is the scan rate. The cyclic voltammograms with different scan rates are shown in Fig. S3a. $\uparrow$ The peak current density shows a linear relationship with the square root of the scan rate (Fig. S3 $\dagger$ ), and the diffusion coefficient was calculated from the slope, which is $2.7 \times 10^{-9} \mathrm{~m}^{2} \mathrm{~s}^{-1}$. This value is very close to the one obtained from the transient time, indicating that the methods used for calculating the diffusion coefficients and the concentration are reliable.

\subsection{ORR in DMSO with $\mathrm{Mn}^{2+}$ ions present}

Cyclic voltammograms of the DMSO solutions containing $0.1 \mathrm{M}$ $\mathrm{Mn}\left(\mathrm{Tf}_{2} \mathrm{~N}\right)_{2}$ with and without dissolved oxygen gas were recorded (Fig. 4). When there was no $\mathrm{O}_{2}$ dissolved in the solution, reduction starts at $-2.50 \mathrm{~V} v s . \mathrm{Ag} / \mathrm{Ag}^{+}$and reaches a peak current density of $-0.024 \mathrm{~A} \mathrm{dm}{ }^{-2}$ at $-2.96 \mathrm{~V} v s . \mathrm{Ag} / \mathrm{Ag}^{+}$on the cathodic scan (Fig. S4 $\dagger$ ). This peak corresponds to the reduction of $\mathrm{Mn}^{2+}$ to $\mathrm{Mn}^{0}$, which was confirmed by EDX (Fig. S5†). The manganese deposit can be oxidized again upon the positive scan, with an oxidation peak position at $-0.39 \mathrm{~V} v s$. Ag and a peak current density of $+0.007 \mathrm{~A} \mathrm{dm}^{-2}$. After dissolving oxygen in the solution, by bubbling oxygen gas through the solution for $30 \mathrm{~min}$, a cyclic voltammogram was measured (Fig. 4, dashed line). When the potential was now scanned negative, a reduction reaction started at $-0.55 \mathrm{~V} v s . \mathrm{Ag} / \mathrm{Ag}^{+}$and resulted in a broad

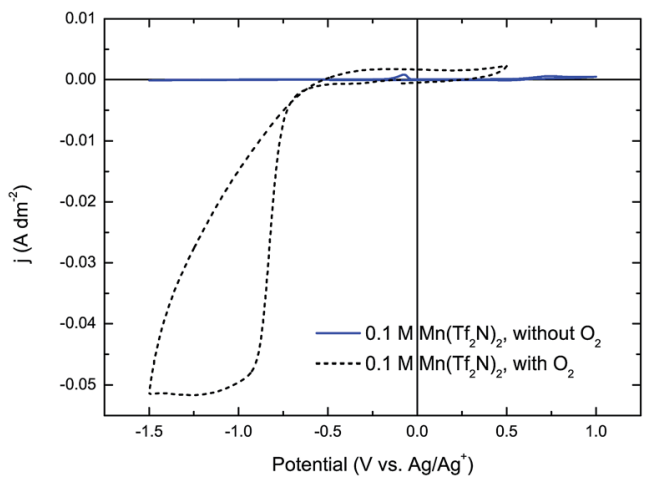

Fig. 4 Cyclic voltammograms of the DMSO solution containing $0.1 \mathrm{M}$ $\mathrm{Mn}\left(\mathrm{Tf}_{2} \mathrm{~N}\right)_{2}$ without dissolved oxygen (blue, solid line) and with dissolved oxygen (black, dashed line). The working electrode was a platinum disk $(\phi=1.5 \mathrm{~mm}$ ). The real reference electrode was a silver wire in a glass tube with frit, filled with $0.1 \mathrm{M} \mathrm{Ag}\left(\mathrm{NO}_{3}\right)$ and $1 \mathrm{MLiTf} 2 \mathrm{~N}$ in DMSO. The counter electrode was a platinum coil and the scan rate was $50 \mathrm{mV} \mathrm{s}^{-1}$

wave up to the vertex potential of $-1.5 \mathrm{~V} v s . \mathrm{Ag} / \mathrm{Ag}^{+}$, with an average current density of $-0.052 \mathrm{~A} \mathrm{dm}^{-2}$. The initial reduction reaction resulting in this broad wave was assigned to the reduction of oxygen to the superoxide radical ion (cfr. eqn (1)). Subsequently the superoxide reacts with manganese cations in solution, forming a $\mathrm{Mn}_{x} \mathrm{O}_{y}$ layer on the electrode. All superoxide radical ions react rapidly with the manganese ions and thus no superoxide can be oxidized upon the positive scan.

The electro-precipitation of manganese oxides was investigated by electrochemical quartz microbalance experiments (Fig. 5). Cyclic voltammograms were used to reduce oxygen followed by a precipitation of $\mathrm{Mn}_{x} \mathrm{O}_{y}$ (Fig. S6 $\dagger$ ). For practical reasons a silver wire was used as the pseudo-reference electrode instead of a real reference electrode as for the other experiments, which can cause a small shift in peak potential for the reduction of oxygen. During the first cycle, the highest reduction current density of $-0.075 \mathrm{~A} \mathrm{dm}^{-2}$ is reached at a potential

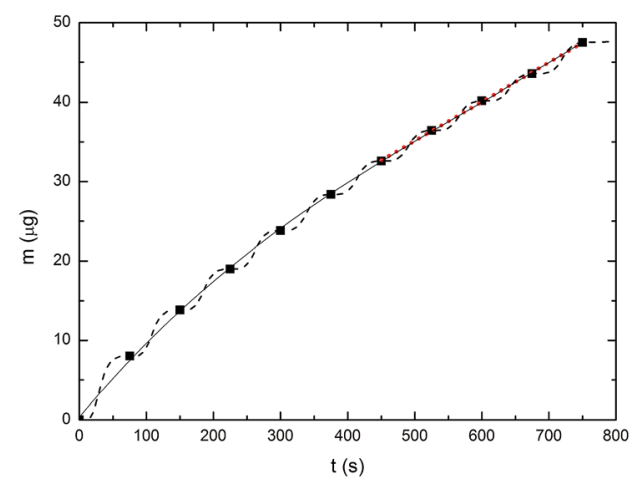

Fig. 5 Mass change was measured by EQCM (dashed line) while performing cyclic voltammetry in an oxygen-saturated DMSO solution with $0.1 \mathrm{M} \mathrm{Mn}\left(\mathrm{Tf}_{2} \mathrm{~N}\right)_{2}$. A platinum coated quartz crystal was used as the working electrode $(\phi=12.7 \mathrm{~mm})$, a platinum coil was used as the counter electrode and a silver wire was used as the pseudo-reference electrode. For the cyclic voltammograms, a scan rate of $50 \mathrm{mV} \mathrm{s}^{-1}$ was applied, with $-1.4 \mathrm{~V}$ and $+0.5 \mathrm{~V}$ vs. Ag as vertex potentials. 


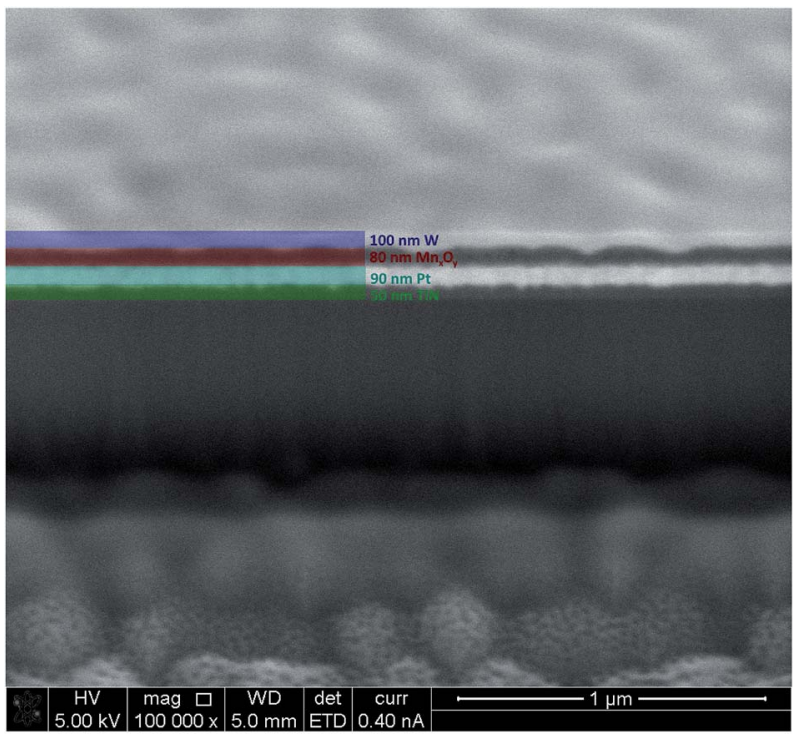

Fig. 6 Electro-precipitated $\mathrm{Mn}_{x} \mathrm{O}_{y}$, deposited via dissolved oxygen reduction in a $0.1 \mathrm{M} \mathrm{Mn}\left(\mathrm{Tf}_{2} \mathrm{~N}\right)_{2}$ in DMSO solution. The deposition was made by applying cyclic voltammetry for 10 cycles with vertex potentials of $-1.4 \mathrm{~V}$ and $+0.5 \mathrm{~V}$ vs. Ag. As substrate and working electrode, a platinum coated $(90 \mathrm{~nm})$ silicon wafer was used with a TiN buffer layer $(50 \mathrm{~nm}$ ). A focussed ion beam of gallium ions was used to etch the sample. To obtain a high-resolution image of the etch pattern, a tungsten layer $(100 \mathrm{~nm})$ was deposited on top of the $80 \mathrm{~nm}$ thick $\mathrm{Mn}_{x} \mathrm{O}_{y}$ layer.

of $-0.9 \mathrm{~V} v s$. Ag. All subsequent cycles have a progressively lower current density and less pronounced peaks are observed. For none of the cycles an oxidation current was observed during the reverse scan. This already indicates that, cycle after cycle, the surface progressively becomes blocked due to the precipitation of non-conductive manganese oxides.

This hypothesis is confirmed by using a RRDE and the mass changes on the quartz crystal microbalance, only a mass increase was observed during cycling and no mass decrease, which leads to the conclusion that manganese oxides are precipitated via oxygen reduction, but not re-oxidized and dissolved during the positive scan. It can be seen that the relative mass increase per cycle $(\Delta m)$ changes upon cycling (Fig. 5). During the first cycle the mass increased by $8.0 \mu \mathrm{g}$, but this $\Delta m$ decreased to $4.5 \mu \mathrm{g}$ for the fifth cycle, after which the $\Delta m$ remains constant with a value of approx. $4 \mu \mathrm{g}$ per cycle. During the first five cycles $\Delta m$ decreases upon cycling due to the surface which becomes progressively blocked due to an insulating $\mathrm{Mn}_{x} \mathrm{O}_{y}$ layer. This insulating layer causes an $i R$-drop, thereby changing the oxygen reduction from a mass-transport controlled reaction to a kinetic controlled reaction, which explains the missing peak in the cyclic voltammogram after the first few cycles (Fig. S6†).

From cycle five to ten, the mass increase per cycle $(\Delta m)$ changes linearly with time (red, dotted line in Fig. 5, with an $R$ square value of 0.99951). The average deposition rate equals $0.049 \mu \mathrm{g} \mathrm{s}^{-1}$. Assuming that $\mathrm{MnO}_{2}$ is the main precipitation product (vide infra), the average growth rate can be estimated using the following equation:

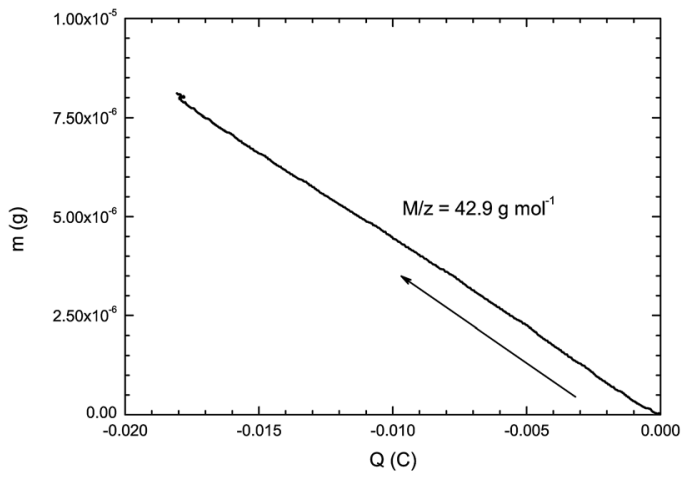

(a) Cycle 1

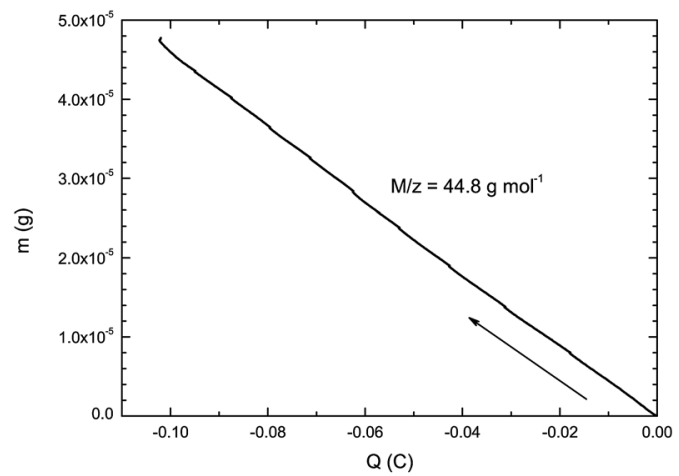

(b) Cycle 1-10

Fig. $7 m$ vs. $Q$ plots based on the cyclic voltammograms in an oxygen-saturated DMSO solution containing $0.1 \mathrm{M} \mathrm{Mn}\left(\mathrm{Tf}_{2} \mathrm{~N}\right)_{2}$. $\mathrm{M} / \mathrm{z}$ values are reported and determined via a linear fit.

$$
r=\frac{d}{\rho A}
$$

where $r$ is the growth rate $\left(\mathrm{m} \mathrm{s}^{-1}\right), d$ is the deposition rate $(\mathrm{g}$ $\left.\mathrm{s}^{-1}\right), \rho$ is the mass density of $\mathrm{MnO}_{2}\left(5.026 \times 10^{6} \mathrm{~g} \mathrm{~m}^{-3}\right)$ and $\mathrm{A}$ is the electrode area of the quartz crystal $\left(1.27 \times 10^{-4} \mathrm{~m}^{2}\right)$. This results in an average growth rate of $0.077 \mathrm{~nm} \mathrm{~s}^{-1}$ or $5.8 \mathrm{~nm}$ per cycle for cycle five to ten of the cyclic voltammogram with a scan rate of $50 \mathrm{mV} \mathrm{s}^{-1}$. The total mass deposited during the experiment is $48 \mu \mathrm{g}$ which corresponds to a $\mathrm{MnO}_{2}$ layer with a thickness of approx. $75 \mathrm{~nm}$. In Fig. 6 it can be seen that the thickness measured by nanoSEM was approx. $80 \mathrm{~nm}$ which is in close agreement with the calculated value based on the EQCM experiment.

EQCM can also be used to gain in situ information about the type of manganese oxide $\left(\mathrm{MnO}, \mathrm{MnO}_{2}, \mathrm{Mn}_{2} \mathrm{O}_{3}\right.$ or $\left.\mathrm{Mn}_{3} \mathrm{O}_{4}\right)$ that is formed during the precipitation reaction. Therefore the Sauerbrey equation is combined with Faraday's law of electrochemistry

$$
m=-C \Delta f
$$

and

$$
m=\frac{M Q}{z \mathrm{~F}}
$$


where $m$ is the mass deposited on the quartz crystal, $Q=\int_{0}^{t} i(\tau) \mathrm{d} \tau$ is the charge in Coulomb, $M$ is the molar mass of the deposited compound, $z$ is the number of electrons in the electrochemical reaction and $C$ is the proportionality constant in the Sauerbrey equation. This constant $C$ was experimentally determined for our EQCM set-up by silver deposition from DMSO. ${ }^{29,30}$

In Fig. 7, the $m$ vs. $Q$ plots are shown for the first cycle (Fig. 7a) and for the overall experiment of ten subsequent cycles (Fig. 7b). The charge $Q$ is calculated by integrating the current over time and the mass $m$ is obtained from experimental $\Delta f$ and eqn (7). From this plot the $M / z$ ratio can be calculated using eqn (8) and the slope of the linear fit which is $M / z \mathrm{~F} . M / z$ is the molar mass of the added load on the crystal over the number of electrons consumed in the reaction. When analyzing the first cycle, a linear fit with an $R$-square value of 0.99979 could be obtained, resulting in a $M / z$ value of $42.9 \mathrm{~g} \mathrm{~mol}^{-1}$ (Fig. 7a). The little curl in the upper left corner of the graph indicates that there is no mass decrease and no positive charge was measured during the cyclic voltammetry. Therefore it was also possible to fit a linear curve for all ten cycles at once, resulting in a $M / z$ value of $44.8 \mathrm{~g} \mathrm{~mol}^{-1}$ with an $R$-square value of 0.99974 (Fig. 7b). These linear fits indicate a directly proportional relationship between $m$ and $Q$, which leads to the conclusion that a fast deposition is obtained and all reduced oxygen molecules precipitate as manganese oxide. This direct proportionality is expected for metal depositions, but unexpected compared to the formation of $\mathrm{Li}_{2} \mathrm{O}_{2}$ in $\mathrm{Li}$-air batteries, where the superoxide is partially soluble in DMSO. ${ }^{31}$ However, as opposed to metal deposition, analyzing the EQCM results for manganese dioxide precipitation can be challenging due to the various compounds that can be formed during precipitation.

There are two ways to clarify the complexity of various possible manganese oxides formed during precipitation. One is to calculate theoretical $M / z$ values and compare these with the experimental value (Table 1 ). Another option is to calculate the experimental $z$ value which corresponds to the various compounds using the experimental $M / z$ (Table 2). Since the $z$ value corresponds with the number of electrons consumed in the reaction, this value has to be an integer. Both methods lead to the same conclusion that $\mathrm{MnO}_{2}$ is the main deposition product during the precipitation reaction involving two electrons.

XRD spectra were measured as-deposited and after annealing at $1000{ }^{\circ} \mathrm{C}$ (Fig. 8). The as-deposited spectrum shows a peak for $\mathrm{MnO}_{2}$ at $27^{\circ}$ and at $32^{\circ}$, the latter disappears upon annealing

Table 1 Theoretical $M / z$ values for various $\mathrm{Mn}_{x} \mathrm{O}_{y}$

\begin{tabular}{lcrrrrr}
\hline & & \multicolumn{1}{c}{$z$} & & \\
\cline { 3 - 7 } Compound & $M / \mathrm{g} \mathrm{mol}^{-1}$ & \multicolumn{1}{c}{1} & 2 & 3 & \multicolumn{1}{c}{4} & \multicolumn{1}{c}{5} \\
\hline $\mathrm{MnO}$ & 70.937 & 70.9 & 35.5 & 23.6 & 17.7 & 14.2 \\
$\mathrm{MnO}_{2}$ & 86.937 & 86.9 & 43.5 & 29.0 & 21.7 & 17.4 \\
$\mathrm{Mn}_{2} \mathrm{O}_{3}$ & 157.87 & 157.9 & 78.9 & 52.6 & 39.5 & 31.6 \\
$\mathrm{Mn}_{3} \mathrm{O}_{4}$ & 228.81 & 228.8 & 114.4 & 76.3 & 57.2 & 45.8
\end{tabular}

Table 2 Theoretical $z$ values for various $\mathrm{Mn}_{x} \mathrm{O}_{y}$ based on the experimental $\mathrm{M} / \mathrm{z}$ ratio

\begin{tabular}{lcll}
\hline & & \multicolumn{2}{l}{} \\
\cline { 3 - 4 } Compound & $M / \mathrm{g} \mathrm{mol}^{-1}$ & Cycle 1 & Cycle 1-10 \\
\hline $\mathrm{MnO}$ & 70.937 & 1.7 & 1.6 \\
$\mathrm{MnO}_{2}$ & 86.937 & 2.0 & 1.9 \\
$\mathrm{Mn}_{2} \mathrm{O}_{3}$ & 157.87 & 3.7 & 3.5 \\
$\mathrm{Mn}_{3} \mathrm{O}_{4}$ & 228.81 & 5.3 & 5.1 \\
\hline
\end{tabular}

whereas the former at $27^{\circ}$ decreases in intensity, but increases again when cooling down the sample (Fig. 9 and S7 $\dagger$ ). Before annealing, next to $\mathrm{MnO}_{2}$, also $\mathrm{Mn}_{2} \mathrm{O}_{3}$ peaks are observed, one at $33^{\circ}$ which increases in intensity after annealing and one extra peak at $23^{\circ}$ only visible after annealing. It is believed that initially a small amount of crystalline $\mathrm{MnO}_{2}$ and $\mathrm{Mn}_{2} \mathrm{O}_{3}$ is deposited next to an amorphous deposition of $\mathrm{Mn}_{x} \mathrm{O}_{y}$. This amorphous deposit crystallizes upon heating into $\mathrm{Mn}_{2} \mathrm{O}_{3}$ at a temperature of $496^{\circ} \mathrm{C}$ (Fig. S8†).

Rotating ring-disk electrode experiments show that the oxygen reduction reaction in $\mathrm{Mn}^{2+}$-containing electrolytes differs from $\mathrm{TBA}^{+}$-containing electrolytes (Fig. 10). Ten subsequent cyclic voltammograms were measured on the disk electrode, while the ring electrode was kept at a constant potential of $-0.7 \mathrm{~V} v s$. $\mathrm{Ag} / \mathrm{Ag}^{+}$. At the latter potential, the oxygen evolution reaction should be in the mass-transport controlled region. Thus an oxidative current should be observed when the superoxide is successfully stabilized in the electrolyte and transported to the ring (Fig. 2). As can be seen in Fig. 10 no oxidative current is observed on the ring, in other words all the superoxide radical ions formed on the disk reacted with manganese cations and are precipitated on the disk. The lack of a plateau feature, replaced instead by a broad peak, in the RRDE curve can be understood by the deposition of an insoluble electrically insulating reduction product $\left(\mathrm{Mn}_{x} \mathrm{O}_{y}\right)$ which blocks the oxygen from reaching the electrochemical interface and thereby prevents the occurrence of a plateau. The precipitation of an insulating layer is also illustrated by the decreasing current density upon cycling, whereas the first cycle reached a peak

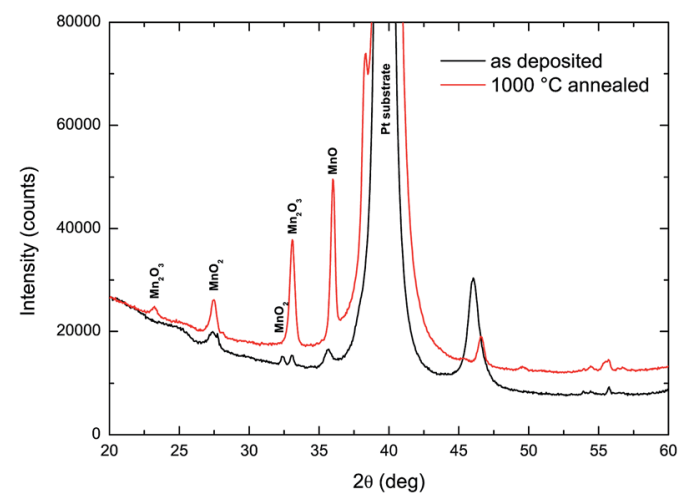

Fig. 8 XRD pattern of the electro-precipitated $\mathrm{Mn}_{x} \mathrm{O}_{y}$ thin film as deposited (black) and after annealing at $1000{ }^{\circ} \mathrm{C}$ (red). 


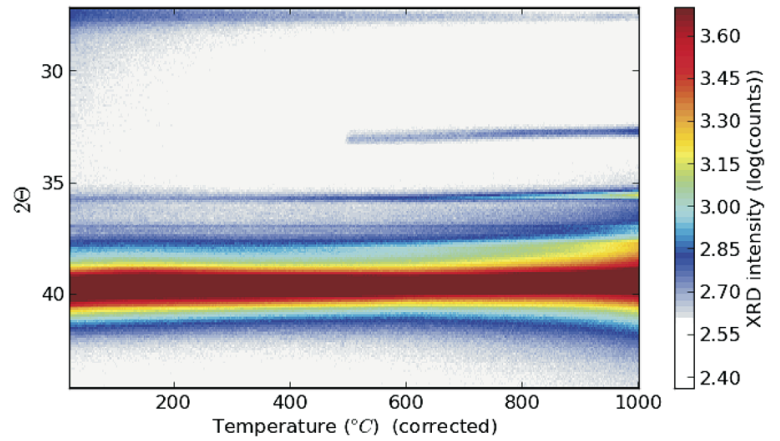

Fig. 9 In situ temperature XRD in air of the electro-precipitated $\mathrm{Mn}_{x} \mathrm{O}_{y}$ thin film.

current of $-1.3 \times 10^{-4} \mathrm{~A}$, and the second only reached a current of $-0.9 \times 10^{-4} \mathrm{~A}$ and decreased further with the cycle number. This decrease cannot be attributed to the decrease of oxygen atoms, because there is a constant flow and transport of oxygen towards the RRDE. Although the RRDE was rotating at $1000 \mathrm{rpm}$ and a thin gap RRDE was used, no current was measured on the ring, which indicates that the precipitation reaction is very fast.

The as-deposited films showed electrochemical activity for both supercapacitor and Li-ion battery applications. Platinum was used as the substrate throughout this study as an inert electrode, although it is highly unlikely that platinum will be used in the final application. Therefore also other substrates were used as current collectors, like carbon nanosheets (height of $20-70 \mathrm{~nm}$ ) and TiN seed layers. As a model for high aspect ratio structures, silicon pillars coated with TiN were used (Fig. S9†). The surface enhancement factor is 5.2.

For the planar platinum substrate, the capacitance was measured at various scan rates for a thin $\mathrm{Mn}_{x} \mathrm{O}_{y}$ film of approx. $80 \mathrm{~nm}$ or $46 \mu \mathrm{g}$. The specific capacitance calculated from the CVs was $259,174,125,96.1$ and $70.0 \mathrm{~F} \mathrm{~g}^{-1}$ for scan rates of 5,50 , 100,200 and $500 \mathrm{mV} \mathrm{s}^{-1}$, respectively (Fig. S10†). For the carbon nanosheet covered substrate the capacitance was a little bit higher. And it maintained a better performance at higher scan rates with $195,185,173$ and $151 \mathrm{~F} \mathrm{~g}^{-1}$ for scan rates of 50,100 , 200 , and $500 \mathrm{mV} \mathrm{s}^{-1}$, respectively (Fig. S11†).

Even more interesting is the performance of the $\mathrm{Mn}_{x} \mathrm{O}_{y}$ film on the $3 \mathrm{D}$ substrate. Due to the self-limiting property of the deposition technique, high aspect ratio structures can be coated. A thin film of approx. $80 \mathrm{~nm}$ was deposited on a planar TiN substrate and a 3D substrate with a surface enhancement of approx. 5 times the surface of the planar substrate. Here the areal specific capacitance is compared for the footprint of the working electrode. For the planar substrate a capacitance of $7.88 \mathrm{mF} \mathrm{cm}^{-2}$ was calculated, whereas for the 3D substrate a capacitance of $37.8 \mathrm{mF} \mathrm{cm}^{-2}$ was obtained. This is 4.8 times higher than the areal capacitance on the planar substrate and thus in close approximation with the area enhancement of the 3D substrate (Fig. 11).

These $\mathrm{Mn}_{x} \mathrm{O}_{y}$ deposits can also be used in Li-ion batteries as cathode materials. Lithiation and delithiation of $\mathrm{MnO}_{2}$ thin films were observed in the $3 \mathrm{~V} v s$. $\mathrm{Li}^{+} / \mathrm{Li}$ range. The performance

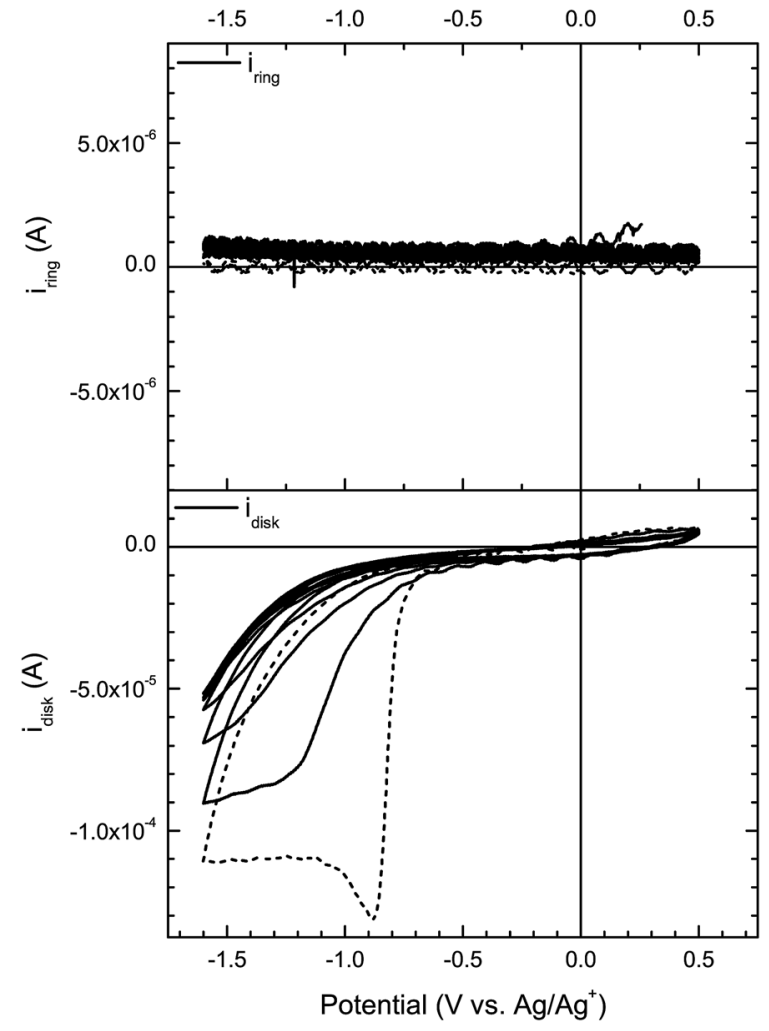

Fig. 10 Disk (bottom) and ring (top) currents recorded in an oxygensaturated $0.1 \mathrm{M} \mathrm{Mn}\left(\mathrm{Tf}_{2} \mathrm{~N}\right)_{2} \mathrm{DMSO}$ solution at $25^{\circ} \mathrm{C}$. The RRDE rotates at a constant speed of $1000 \mathrm{rpm}$. On the disk cyclic voltammograms were measured with a scan rate of $50 \mathrm{mV} \mathrm{s}^{-1}$ and the ring was kept at a constant potential of $-0.7 \mathrm{~V} v \mathrm{~s}$. $\mathrm{Ag} / \mathrm{Ag}^{+}$.

of this film depends however on the thickness as has been shown in the literature. ${ }^{32} \mathrm{~A}$ film of approx. $300 \mathrm{~nm}$ was deposited on the substrate with carbon nanosheets (height $2 \mu \mathrm{m}$ ). The performance of the film increased upon cycling (Fig. S12†). This is probably due to the increase of porosity upon cycling and thus a better accessibility for the electrolyte and the lithium

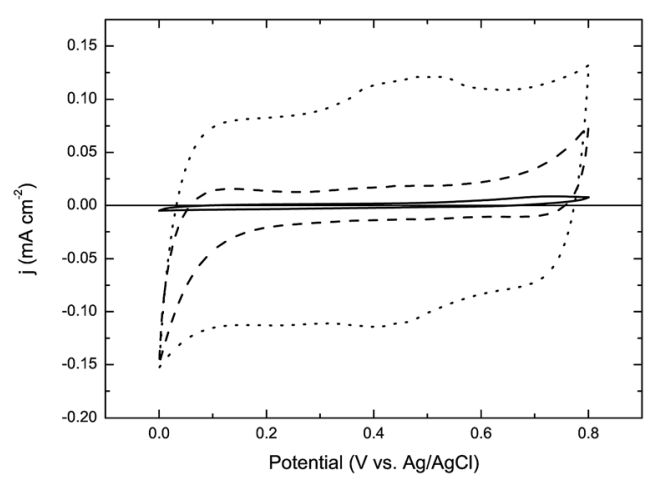

Fig. 11 Capacitance measured via cyclic voltammetry in $0.5 \mathrm{M} \mathrm{K}_{2} \mathrm{SO}_{4}$ aqueous electrolyte using a Pt counter electrode and an $\mathrm{Ag} / \mathrm{AgCl}$ reference electrode. $\mathrm{A} \mathrm{Mn}_{x} \mathrm{O}_{y}$ thin film of approx. $80 \mathrm{~nm}$ was deposited on a planar TiN working electrode (dashed) and on TiN coated Si pillars as the 3D substrate (dotted). The capacitance of the pillars without $\mathrm{Mn}_{x} \mathrm{O}_{y}$ (solid) is shown as a reference. 
ions. It should be noticed that normally electrode materials are post-treated, e.g. heat annealed, to improve the performance of the materials. Here the electrochemical energy storage data were measured on the as-deposited films.

\section{Conclusions}

Electro-precipitation of manganese oxide via dissolved oxygen reduction is a fast, self-limiting deposition technique suited for the deposition of thin films for all-solid-state lithium-ion batteries. The fast precipitation reaction was proven by using a thin gap rotating ring disk electrode, which also illustrated the self-limiting property of the electro-precipitation reaction. Electrochemical quartz crystal microbalance (EQCM) was used as an in situ technique to study the deposition mechanism, which led to the conclusion that a two electron reduction resulted in the electro-precipitation of $\mathrm{MnO}_{2}$ at a growth rate of $0.077 \mathrm{~nm} \mathrm{~s}^{-1}$. Since the XRD pattern shows no characteristic $\mathrm{MnO}_{2}$ peak, post-treatments are necessary to obtain the correct $\mathrm{MnO}_{2}$ crystal structure that is needed for lithium-ion batteries and/or supercapacitors.

\section{Acknowledgements}

The authors acknowledge financial support by the IWT-Flanders (SBO project IWT 18142 "SoS-Lion"). We thank Joop van Deursen for making and designing the EQCM cell and Jeroen Sniekers for the synthesis of $\operatorname{Mn}\left(\mathrm{Tf}_{2} \mathrm{~N}\right)_{2}$.

\section{References}

1 A. Patil, V. Patil, D. W. Shin, J.-W. Choi, D.-S. Paik and S.-J. Yoon, Mater. Res. Bull., 2008, 43, 1913-1942.

2 L. Baggetto, R. A. H. Niessen, F. Roozeboom and P. H. L. Notten, Adv. Funct. Mater., 2008, 18, 1057-1066.

3 W. L. Jeffrey, B. Dunn, R. R. Debra and S. W. Henry, Chem. Rev., 2004, 104, 4463-4492.

4 P. Notten, F. Roozeboom, R. Niessen and L. Baggetto, Adv. Mater., 2007, 19, 4564-4567.

5 M. Armand and J.-M. Tarascon, Nature, 2008, 451, 652-657.

6 D. R. Rolison, J. W. Long, J. C. Lytle, A. E. Fischer, C. P. Rhodes, T. M. McEvoy, M. E. Bourg and A. M. Lubers, Chem. Soc. Rev., 2009, 38, 226-252.

7 C. P. Rhodes, J. W. Long, M. S. Doescher, B. M. Dening and D. R. Rolison, J. Non-Cryst. Solids, 2004, 350, 73.

8 S. Deheryan, D. Cott, R. Muller, M. Timmermans, M. Heyns and P. Vereecken, Carbon, 2015, 88, 42-50.
9 C. Johnson, J. Power Sources, 2007, 165, 559.

10 F. Tedjar and J. Guitton, Thermochim. Acta, 1991, 13, 181.

11 F. Petit, J. Durr, M. Lenglet and B. Hannoyer, Mater. Res. Bull., 1993, 28, 959.

12 T. Nohma, T. Saito, N. Furukawa and H. Ikeda, J. Power Sources, 1989, 26, 389.

13 M. Ghaemi and L. Binder, J. Power Sources, 2002, 111, 248254.

14 C. J. Clarke, G. J. Browning and S. W. Donne, Electrochim. Acta, 2006, 51, 5773-5784.

15 S. Sarciaux, A. L. G. L. Selle, A. Verbaere, Y. Piffard and D. Guyomard, J. Power Sources, 1999, 81-82, 656-660.

16 S. Sarciaux, A. L. G. L. Selle, A. Verbaere, Y. Piffard and D. Guyomard, J. Power Sources, 1999, 81-82, 661-665.

17 V. Augustyn, P. Simon and B. Dunn, Energy Environ. Sci., 2014, 7, 1597-1614.

18 O. Ghodbane, J.-L. Pascal and F. Favier, ACS Appl. Mater. Interfaces, 2009, 1, 1130-1139.

19 M. Toupin, T. Brousse and D. Bélanger, Chem. Mater., 2004, 16, 3184-3190.

20 A. Cross, A. Morel, A. Cormie, T. Hollenkamp and S. Donne, J. Power Sources, 2011, 196, 7847-7853.

21 A. D. Cross, A. Morel, T. F. Hollenkamp and S. W. Donne, J. Electrochem. Soc., 2011, 158, A1160-A1165.

22 H. Lee, J. Kang, M. S. Cho, J.-B. Choi and Y. Lee, J. Mater. Chem., 2011, 21, 18215-18219.

23 Z. Li, Y. Mi, X. Liu, S. Liu, S. Yang and J. Wang, J. Mater. Chem., 2011, 21, 14706-14711.

24 S. Chen, J. Zhu, X. Wu, Q. Han and X. Wang, ACS Nano, 2010, 4, 2822-2830.

25 S. Grover, S. Shekhar, R. K. Sharma and G. Singh, Electrochim. Acta, 2014, 116, 137-145.

26 W. Knaepen, C. Detavernier, R. V. Meirhaeghe, J. J. Sweet and C. Lavoie, Thin Solid Films, 2008, 516, 4946-4952.

27 C. O. Laoire, S. Mukerjee, K. M. Abraham, E. J. Plichta and M. A. Hendrickson, J. Phys. Chem. C, 2010, 114, 9178-9186.

28 F. Gan and D.-T. Chin, J. Appl. Electrochem., 1993, 23, 452455.

29 C. Gabrielli, M. Keddam and R. Torresi, J. Electrochem. Soc., 1991, 138, 2657-2660.

30 G. Vatankhah, J. Lessard, G. Jerkiewicz, A. Zolfaghari and B. E. Conway, Electrochim. Acta, 2003, 48, 1613-1622.

31 S. Schaltin, G. Vanhoutte, M. Wu, F. Barde and J. Fransaer, Phys. Chem. Chem. Phys., 2015, 17, 12575-12586.

32 A. S. Etman, A. Radisic, M. M. Emara, C. Huyghebaert and P. M. Vereecken, J. Phys. Chem. C, 2014, 118, 9889-9898. 